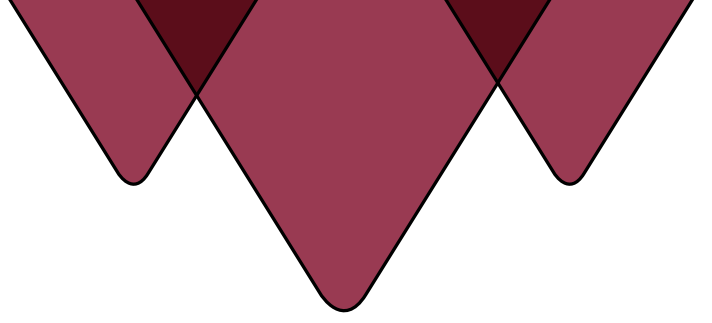

\title{
Time, New Public Management, and Canadian Academic Librarians' Scholarship and Service
}

\author{
Karen P. Nicholson \\ University of Guelph / University of Western Ontario
}

\begin{abstract}
Time is a critical factor in the success of librarians' scholarship. Shared perceptions of organizational time enable, regulate, and constrain performance. Under the values and practices of New Public Management (NPM), intended to increase accountability and efficiency in the public sector, time in the university has become accelerated, intensified, fragmented, and commodified. Feminist and anti-colonial scholars remind us of the differentiated temporal impacts of NPM on women and other minorities in higher education, yet to date, its impact on the feminized profession of librarianship has not been examined. Using data from semi-structured interviews with 24 librarians working in Canadian UI5 public research-intensive universities, the present article seeks to address this gap by exploring the impact of neoliberal timescapes on librarians' scholarship and professional-service activities. Findings indicate that time is an important mechanism through which neoliberal governmentality is enacted. Being a "successful" researcher is largely dependent on intrinsic motivation and self-regulation. Trying to work with, rather than against, neoliberal timescapes facilitates research. Results also suggest that conflicting organizational timescapes may exist between library directors and librarians, and that, as researchers, Canadian academic librarians are being held accountable to ambiguous performance standards and impracticable timescapes.
\end{abstract}

Keywords: academic librarians · Canada - higher education - neoliberalism - New Public Management $\cdot$ research $\cdot$ scholarship $\cdot$ service $\cdot$ time timescape

\section{RÉSUMÉ}

Le temps est un facteur de réussite critique quant à l'érudition des bibliothécaires. Les perceptions partagées du temps organisationnel permettent, régulent et limitent le rendement. En vertu des valeurs et des pratiques de la nouvelle gestion publique (NGP), qui visent à accroître la responsabilisation et l'efficience dans le secteur public, le temps passé à l'université s'est accéléré, intensifié, fragmenté et marchandisé. Les universitaires féministes et anticoloniaux nous rappellent les impacts temporels différenciés de la NGP sur les femmes et les autres minorités dans l'enseignement supérieur, mais à ce jour, son impact sur la profession féminisée de bibliothécaire 
n'a pas été examiné. À l'aide de données tirées d'entrevues semi-structurées menées auprès de 24 bibliothécaires travaillant dans des universités publiques canadiennes à forte intensité de recherche du UI5, le présent article cherche à combler cette lacune en examinant l'impact des paramètres temporels néolibéraux sur les activités d'érudition et de services professionnels des bibliothécaires. Les résultats indiquent que le temps est un mécanisme important par lequel la gouvernementalité néolibérale est mise en ouvre. La réussite d'un chercheur dépend en grande partie de sa motivation intrinsèque et de son autorégulation. Tenter de travailler avec les paramètres temporels néolibéraux, plutôt qu'à l'encontre de ceux-ci, facilite la recherche. Les résultats suggèrent également qu'il peut exister des situations organisationnelles conflictuelles entre la direction des bibliothèques et les bibliothécaires et que, en tant que chercheurs, les bibliothécaires universitaires canadiens doivent respecter des normes de rendement ambiguës et des paramètres temporels impraticables.

Mots-clés: bibliothécaires universitaires · Canada · enseignement supérieur . érudition néolibéralisme - nouvelle gestion publique · paramètres temporels recherche $\cdot$ service $\cdot$ temps

\section{$\mathbf{S}_{0}$} ometimes referred to as "practitioner researchers," academic librarians engage in professional practice, scholarship, and professional service as part of their regular duties. ${ }^{\mathrm{I}}$ Factors contributing to the success of librarians' scholarship have been well documented in the LIS literature. Time, above all, is critical (Berg, Jacobs, and Cornwall 20I3).

Shared perceptions of organizational time enable, regulate, and constrain performance (Adam 1990): "the management of work ... workers and the discipline of work involves the management of time" (Bansel and Davies 2005, 53). In the academy, time structures the institutional mission and impacts research and pedagogy (Giroux and Giroux 2004). The values and practices of New Public Management (NPM), intended to increase accountability and efficiency in the public sector, have impacted the university's timescape (Adam 2008) ${ }^{2}$ : time has become accelerated, intensified, fragmented, and commodified (Bansel and Davies 2005; Giroux and Giroux 2004; Menzies and Newson 2007; Walker 2009; Ylijoki and Mäntylä 2003). Feminist and anti-colonial scholars remind us of the differentiated temporal impacts of New Public Management on white women and people of colour in higher education (Davies et al. 2005; Mountz et al. 2015; Moss 2006; Menzies and Newson 2007; Shahjahan 2015;

I. I have used "scholarship" to describe research, scholarship, and scholarly activities. "Professional service" is used to refer to service to the library, the university, or the profession in order to distinguish it from public-service activities such as reference or information literacy instruction. Sabbaticals, research leaves, and study leaves are referred to as "research leaves."

2. "Timescape" emphasizes the importance of context to our experience of time by recognizing the interrelatedness of time, spatiality, and matter. "A timescapes perspective acknowledges this spatiality, materiality, contextuality but foregrounds the temporal side of the interdependency" (Adam 2008, I, original emphasis). A timescape is a situated time, one that includes time frame, timing, tempo, and temporality. 
Thomas and Davies 2002). As members of a feminized profession (Harris 1992), marginal educators not neatly classified as faculty or academic staff(Sloniowski 2016), to what extent are librarians' scholarship and professional-service activities also subject to neoliberal temporal logics?

According to Moss $(2006,3)$, "prioritizing time and space in study design and analysis" enables the researcher "to relate personal experiences to broader socioeconomic and political issues." This study draws on interdisciplinary analyses of time to situate the work of Canadian academic librarians within the context of a university subject to the logics and practices of New Public Management. Using data gathered from interviews with 24 information literacy librarians employed in Canada's UI5 universities, ${ }^{3}$ it adds to the existing literature on librarians as researchers by examining the impact of the neoliberal university's timescape on their scholarship and professional-service activities.

\section{Literature Review}

\section{Time, New Public Management, and the Neoliberal Subject}

The incursion of neoliberal values and practices into the higher-education systems of OECD countries, resulting from successive policy shifts from the I970s on and facilitated by the principles and practices of New Public Management, has been well documented (e.g., Harvey 2007; Hood I99I; Olssen and Peters 2005; Shore 2008 and 20I0; Slaughter and Leslie 1997). New Public Management (NPM) is an array of "broadly similar administrative doctrines" (Hood I99I, 3) intended to increase effectiveness and efficiency in the public sector through the introduction of private-sector values (e.g., competition, frugality, risk, choice, value for money, entrepreneurship), practices (e.g., accountability and audit), and tools (e.g., strategic plans, scorecards) (Hood I99I; Olssen and Peters 2005). Hood (I99I, 4-5) identifies the following additional features of NPM: "hands-on professional management," the explicit use of standards and performance indicators, a focus on outputs/results over procedures, the "unbundling" of larger units into smaller, flexible, corporatized ones (e.g., teams), frugality in resource allocation, and the elimination of inefficiencies. Just-in-time inventory systems and the use of money and time as measures of success (or failure) are also pervasive. Under NPM, education no longer represents a public good but instead becomes "an input-output system which can be reduced to an

3. The Ui5 group of universities represents Canada's most research-intensive universities. Twelve are English-language institutions and two are French; the final member, the University of Ottawa, offers programs in both languages. English-language members include (from east to west): Dalhousie, McGill, University of Ottawa, Queen's, University of Toronto, York, McMaster, University of Waterloo, University of Western Ontario, University of Manitoba, University of Saskatchewan, University of Alberta, University of Calgary, and University of British Columbia. The Université de Montréal and Université Laval represent the French-language institutions. 
economic production function" (Olssen and Peters 2005, 324), a privileged site for the reproduction of human capital. Because "neoliberal work" is associated with "the ideal of self-realization" (Elliott 20I8, I286; Rottenberg 20I3; Spence 2015), public-sector knowledge workers act as self-regulating, collaborative, team-focused entrepreneurs (Bansel and Davies 2005; Berkovich and Wasserman 20I7; Hancock and Spicer 20I0). ${ }^{4}$

Critical and empirical studies demonstrate that the values and practices of NPM have impacted the university's timescape (Adam 2008): time has become accelerated, intensified, fragmented, and commodified (Bansel and Davies 2005; Giroux and Giroux 2004; Menzies and Newson 2007; Walker 2009; Ylijoki and Mäntylä 2003). The workday has become highly scheduled and increasingly long, as work time and personal time blur. Quality has become less about "the nature of the work, of the thought, of the interaction," and more about producing quantifiable results in greater number and less time (Bansel and Davies 2005, 52). Complex and often conflicting temporal orders exist within the academy, including

the highly scheduled and regulated rhythm of bureaucrats, managed professionals, and student-clients; the urgent, contracted time of the academic as entrepreneur and adjunct . . . the deferred time of education as training for future employment; and the endless time of lifelong learning. (Nicholson 2016, 29)

Using data gathered from interviews with Finnish academics, Ylijoki and Mäntylä (2003) examine the impact of NPM on the university's timescape and identify the following four temporal perspectives: scheduled time, timeless time, contracted time, and personal time. Scheduled time, the time of externally imposed timetables, deadlines, meetings, and lectures, dominates. Scheduled time is accelerated, leaving academics feeling "they have lost control over time" $(2003,62)$. It is also commodified: it can be banked, borrowed, or stolen. In contrast, timeless time, characterized by the internally motivated use of time in which "clock time loses its significance" and one "transcend[s] time and one's self" $(2003,63)$, is the kind of time conducive to scholarship. Timeless time is an ideal rather than an everyday reality.

Feminist and anticolonial scholars remind us of the differentiated temporal impacts of NPM on white women and people of colour in higher education (Davies et al. 2005; Mountz et al. 2015; Moss 2006; Menzies and Newson 2007; Shahjahan 2015; Thomas and Davies 2002). The impact of NPM's "audit culture" on members of these

4. For a comparison of Foucauldian and Marxist interpretations of work under neoliberalism, see Elliott 2018.

5. Contracted time is characterized by "a sense of time as something that is terminating combined with an uncertainty of the future" (Ylijoki and Mäntylä 2003, 65). Personal time is grounded in personal reflection and represents the space and time devoted to work and other important aspects of one's life such as "how to use your lifetime, how to combine work and other areas of life such as family, and ultimately, how to live a good life" (Ylijoki and Mäntylä 2003, 67). 
groups is particularly well summarized in the following passage written by a group of feminist geographers in Canada and the US:

This counting imperative simultaneously informs our identities and interactions, both scholarly and personal. Counting culture leads to intense, insidious forms of institutional shaming, subject-making, and self-surveillance. It compels us to enumerate and self-audit, rather than listen and converse, engage with colleagues, students, friends and family, or involve ourselves in the meaningful and time-consuming work that supports and engages our research and broader communities. (Mountz et al. 2015, I242-43)

While "taking a gender perspective for understanding the enactment of NPM in public service organizations" (Thomas and Davies 2002, 373) is now commonplace, to date, the impacts of NPM on academic librarians, members of a feminized profession (Harris 1992) and marginal educators on the university campus, remain to be examined.

\section{Time and Academic Librarians}

Recent LIS literature has paid some attention to time (Davies and McKenzie 2002; Savolainen 2006; Chen and Rieh 2009; Hartel 20I0; Allen 20II; Anderson 20I3; Crescenzi, Capra, and Arguello 20I3; Mizrachi and Bates 20I3; Poirier and Robinson 20I4; Hicks and Schindel 20I6). In their study of librarians' perceptions of time while providing reference and information service, Bossaller, Burns, and VanScoy (20I7) conclude that librarians may create self-imposed time pressures as a result of professional values anchored in efficiency and saving the user's time. ${ }^{6}$

Few have considered time in the context of the neoliberal academic library. Quinn (2000) and Nicholson (2015) suggest that academic libraries have become subject to "McDonaldization," the influence of consumer capitalist values through processes of rationalization characterized by efficiency, predictability, calculability, and control. Just-in-time service-delivery models are a key feature of this environment. Drabinski (2OI4) uses the concept of kairos, a kind of contextually sensitive time, to situate the emergence of information literacy within neoliberal reforms to higher education. Building on Drabinski's analysis, I argued in previous work (Nicholson $2016,26)$ that using time as a lens allows us to reconceptualize information literacy as "a construct developed for and taught within the broader context of the neoliberal university, which embraces a skills agenda." If librarians have struggled to move

6. As a profession, librarianship is founded in the principles of scientific management, intended to increase efficiency, effectiveness, and productivity through the streamlining and standardization of work routines (Gregory and Higgins 2018; Kont 2013). Gregory and Higgins (2018) contend that the spread of libraries and the establishment of library science as a field of study and a profession in the US during the Progressive Era (1890-1920) coincided with the rise of private enterprise and the efficiency movement. As a result, libraries were built in the image and model of corporations, and library education and training "was designed to create efficient, pragmatic workers, who were often underpaid (undervalued) women" (25). 
beyond the dominant one-shot information literacy guest-lecture model, with its "superficial, skills-oriented approach," it is because "the one-shot is in perfect sync with the accelerated, fragmented 'corporate time' of contemporary higher education" (Nicholson 20I6, 27). Slow approaches to information behaviour and library work have been explored by Poirier and Robinson (20I4), Nicholson (20I6), and Glassman (2017).

In related work, Ryan and Sloniowski (20I3) describe the intensification of work in the "public academic library" as a barrier to developing a more critical pedagogy for information literacy instruction. Anthropologists Lanclos and Asher (2016, n.p.) identify lack of time as one of the main obstacles to implementing "more widespread and deeply practiced ... ethnographic methods" in academic libraries as an alternative to "analytics and quantitative measures of effectiveness." More theoretically informed ethnographic work, which requires time and expertise, "feels too risky" in a context in which "cash-strapped, results-oriented" library directors want "swift, easy to understand payoffs."

\section{Librarians as Researchers}

Librarians' research needs and practices have also been explored in the literature. Barriers to success include a lack of time, institutional support, funding, and training (Powell, Baker, and Mika 2002, cited in Berg, Jacobs, and Cornwall 2013, 56I). Contributors to success include education, experience, confidence, academic freedom, intrinsic motivation, time, and institutional supports such as peer support groups, mentoring, training, access to library resources, and funding (Detlor and Lewis 2015; Hoffmann, Berg, and Koufogiannakis 20I4; Hollister 20I6; Kennedy and Brancolini 2OI2; Sassen and Wahl 2OI4).

Two studies of Canadian academic librarians are of particular note. In a survey of librarians in Canadian research universities, Fox (2007) found that respondents who were expected or encouraged to engage in scholarship spent fewer than five hours per week doing so. There are no norms for "the appropriate balance between scholarship and other professional responsibilities" $(2007,452)$. Less than 25 percent had taken advantage of available leaves. Librarians often used evenings and weekends to work on scholarship.

Berg, Jacobs, and Cornwall (2013) explored Canadian Association of Research Libraries (CARL) directors' perspectives on academic librarians' research. At threequarters of responding institutions, "there was no recommended amount of time" for librarians' research $(2013,567)$. Nonetheless, most directors wanted librarians to spend significantly more time doing research, "up to 25 percent more" $(2013,567)$. Expectations for research were "inconsistent," and formal documentation outlining 
criteria for "annual review, promotion, and/or tenure" was lacking $(2013,563)$. Directors believed librarians overestimated systemic barriers to success, such as time, funding, and support, and underestimated individual barriers, such as skills and motivation. Conversely, they perceived systemic factors, including institutional expectations, collective agreements, and a culture of evidence-based decisionmaking, to be key facilitators.

\section{Method}

This qualitative study was part of a doctoral research project (Nicholson 2018). Qualitative research seeks to describe and explain cultural experience and meaning (Corbin and Strauss 2008). The broader research project explored the ways that information literacy librarians experience the neoliberal logics and timescapes of the Canadian research-intensive university across their roles and responsibilities.

\section{Sampling and Recruitment}

English-language members of the UI5 group of public, research-intensive universities were selected as sites because they represent the type of institution that Slaughter and Leslie (1997) examined in their study of the impact of neoliberal reforms on higher education, and they form a relatively homogenous group in terms of funding models, organizational structure, and libraries. Study sites were prioritized according to geographic location, research income, and enrolment (See Appendix A).

Target institutions were identified with the goal of recruiting Io to 25 participants from institutions across the country with a range of enrolments and research income. Potential interviewees were identified based on job title and recruited via email and a posting on the researcher's Twitter account. Participants signed a consent form. The University of Western Ontario's Non-Medical Research Ethics Board approved the study.

The twenty-four participants hailed from ten Ui5 institutions in six provinces across the country. Years of experience ranged from less than one year to more than 30. ${ }^{7}$ Eight participants were early career ( $\mathrm{O}-7$ years' experience), nine were mid-career (8-20 years' experience), and seven were late career ( $>20$ years' experience). Average years of experience was 13.26, just above the national average of II.7 in 2OI3-I4 (CAUT 2017). Eighteen participants had tenure or "continuing appointment," one was in a tenure-track position, and the remaining five were contractually employed. No other demographic data was gathered during the interviews.

The trustworthiness (Lincoln and Guba 1986) of this study was enhanced in a number of ways. First, interviewing librarians across Ui5 institutions served as

7. Numbers have been been approximated to protect participants' anonymity. 
a form of site triangulation, enhancing credibility, fairness, and confirmability (Shenton 2004). As insights and themes emerged, negative cases were actively sought out (Lincoln and Guba 1986; Shenton 2004). Initial findings, based in a sample of eight interviews representing participants at all career stages across institutions and provinces, were presented at two Canadian conferences for academic librarians held in 2017. ${ }^{8}$ These presentations provided an opportunity to engage in "member checking," namely, to determine the extent to which the community members "read" the data in the same way that I did (this was done using excerpts from interview transcripts) and the degree to which the experiences of study participants' narratives resonated with their own, and to identify blind spots in the analysis (Lincoln and Guba 1986; Patton 1999). Finally, the research findings were compared to the existing literature, a key strategy "for evaluating works of qualitative inquiry" (Shenton 2004, 69).

\section{Data Collection}

Data was gathered using semi-structured interviews, conducted online using Skype and lasting approximately 90 minutes each. ${ }^{9}$ Interviews focused on four broad areas: information literacy, change, work, and scholarship and service (see Appendix B). Questions were pre-tested with two information literacy librarians. I audio recorded and transcribed the interviews. Interviews were transcribed verbatim, including affect (e.g., laughter) and speech disfluencies, such as "um" and "ah." The data was managed and coded using NVivo.

\section{Data Analysis}

Data was analyzed using thematic analysis within a constructionist framework. Thematic analysis is often used in combination with discourse analysis, interpretive phenomenological analysis, and grounded theory. As a stand-alone method in the social sciences, it is becoming increasingly widespread, however. ${ }^{\text {Io }}$ Within a

8. K. P. Nicholson. 20I7, May. "'Politics and Stress,' 'Playing the Game,' and 'Beating the Clock': Exploring Narratives of Information Literacy Work in the Corporate University in Canada." Workshop for Instruction in Library Use (WILU), Edmonton; K. P. Nicholson. 20I7, June. "Critical Reflections: Exploring Narratives of Librarianship in the Corporate Research-Intensive University in Canada." Canadian Association of Professional Academic Librarians (CAPAL) annual conference, Toronto.

9. Two librarians participated in follow-up interviews at the researcher's request: in one case, to complete the interview; in the other, to seek clarification regarding some of the participant's responses. Follow-up interviews were transcribed and included in the data set.

IO. For example, a search for ("thematic analysis" NOT "grounded theory") within the Library and Information Science Full Text Database yielded 94 results published in academic journals since 2003, with 93 of these items published since 20IO. A search for ("thematic analysis" NOT "discourse analysis") produced 99 results in academic journals. Limiting these two searches to studies with interviews left $5 \mathrm{I}$ and 53 results, respectively. On its own, thematic analysis has recently been used in both qualitative and mixed-methods research in LIS to explore such diverse topics as information resources (Parbhoo and Fourie 20I7); information-seeking behaviour (Orlu 20I6); information-sharing among women with hypertension (Jones et al. 20I8) and on social media (Bronstein 20I4; Panahi, Watson, and Partridge 
constructionist framework, thematic analysis assumes "meaning and experience are socially produced and reproduced" and seeks "to theorize the sociocultural contexts, and structural conditions" behind them (Braun and Clarke 2006, 85).

The data was coded using a latent theoretical approach proposed by Braun and Clarke (2006). The first phase involved writing initial memos, transcribing, and taking notes on potential codes. Next, initial codes were generated and applied using an open coding approach. Similar to the approach taken by Bossaller, Burns, and VanScoy $(2017,7)$, "meaningful words, phrases, or concepts" identified through inductive coding were created and assigned, along with codes representing "key theoretical concepts from the literature," such as acceleration and intensification. Coded data extracts were collated and analyzed to identify emerging themes. The internal homogeneity (meaningful coherence) and external heterogeneity (clear distinctions) of themes was considered (Braun and Clarke 2006). Analysis was recursive, using a process that "involves ... moving back and forward between the entire data set, the coded extracts of data," and the emerging themes (Braun and Clarke 2006, 86). Results documented librarians' experiences of time while engaged in scholarship and professional service and suggested possible explanations for them.

In the analysis that follows, numbers have been used to identify participants because pseudonyms connote gender, cultural, or racial identities that may not reflect those of participants. Similarly, I have used "they" rather than s/he. Information about interviewees' career stage is provided the first time each interviewee is mentioned. Universities have been categorized by total enrolment, using data from the Ui5 group website, as follows: small: up to 25 ooo students (three institutions); mid-sized: 25000 to 35000 students (five institutions); large: more than 35000 students (five institutions). These somewhat arbitrary categories have been used to mask the identities of the universities and the respondents by placing institutions in groups with three or more members. Conventions used when quoting participants are as follows: omissions are indicated by an ellipsis within square brackets, i.e., [. . .], and pauses in speech are indicated by an ellipsis. Speech disfluencies have been omitted for readability.

20I6); medical coding (Lucyk, Tang, and Quan 20I7); and public libraries (Most 2OII). Recent studies by Flierl et al. (20I8) and Yevelson-Shorsher and Bronstein (20I8) use thematic analysis to explore international students' familiarity with and perceptions of academic libraries, and librarian, faculty, and student perceptions of information literacy, respectively. Of particular relevance is Bossaller, Burns, and VanScoy's (20I7) secondary thematic analysis of librarians' experiences of time while providing reference and information service. 


\section{Findings: Time for Scholarship?}

In keeping with existing research related to faculty, academic librarians experienced time as intensified, fragmented, and accelerated. ${ }^{\text {II }}$ Cycles of intense work required them to change priorities and schedules. Daily tasks were interrupted by meetings, consultations, reference shifts, and teaching. It was important to work quickly and efficiently and to track, manage, and report on one's time using calendars, spreadsheets, and databases. Paradoxically, working beyond regular hours, to check email in particular, was also seen as efficient.

Respondents struggled to fit scholarship into the workday. Scholarly activities were regularly put aside in order to accomplish other work, primarily serving faculty and students. Professional service was sometimes prioritized over scholarship because, for the most part, it took place during the workday. Aligning scholarship and professional-practice interests was a common strategy for getting administrative buy-in and researching "efficiently." Nonetheless, even these more "practical" projects did not easily fit within the workday, requiring librarians to devote evenings and weekends to them. The significant time investment required to undertake research in a new area posed a barrier to the diversity of librarians' scholarship. These themes will be explored below.

In the accelerated timescape of the neoliberal university, research was "crammed," "carved," "baked," "blocked," "front loaded" or "back loaded" into schedules. Several librarians mentioned colour-coding their calendars to identify time designated for scholarship and stay on track. Overcrowded schedules posed challenges to collaborative research projects. Working under the pressure of deadlines was a strategy mentioned by several interviewees. Participant I6, a late-career librarian at a mid-sized university, commented,

I think probably my preferred pace, since I like working to deadlines, is to be able to blitz

something and get it done [...] move on, do something else or something more fun.... And writing articles, I mean, yeah I think it probably stems from having been a delinquent write-it-the-night-before essay type of person [laughs]. I've just conditioned myself to do that.

Although such an approach is "delinquent" or less than optimal-reflection and critical thinking are typically associated with slowness-it is, in fact, in sync with "structured time" (Ylijoki and Mäntylä 2003). As a result, this participant had "conditioned" themselves to write at this accelerated tempo until it had become routine.

II. Although some librarians have faculty status, "faculty" here refers to professors and other instructors. 
Scholarship, often presented as a distraction from more pressing or important work, was regularly put on the "back burner," "pushed back," "put on hold," or "put aside," making consistent progress challenging. Summer time, used to accomplish work requiring longer periods of uninterrupted time, was increasingly taken over by system-wide projects with compressed timelines and inflexible deadlines. As a result, research was "chunked" or "parsed" into pieces more easily accomplished in small blocks of time.

Finding the time to stay abreast of changes in the field was difficult for some. Asked what they would like to change about their work, Participant 2I, an earlycareer librarian at a mid-sized institution, replied,

I just can't find time to keep up with librarianship as a profession, [. . . to see what people are saying, and how things are changing, and what the new guidelines say, and so I don't, I feel like a lesser librarian because I just can't find the time to do that so somehow, if I can change anything, I would probably somehow magically create time to do that kind of stuff so I could feel like I'm a part of this profession, you know?

Because staying abreast of the literature was important for staying connected to the profession, most interviewees focused their reading on their practice. Strategies for reading were accelerated and efficient and included browsing Twitter and "skimming" and "scanning" tables of contents, abstracts, and articles.

Librarians' scholarship interests were also primarily aligned with their practice. This strategy helped to secure managerial approval for research and make research "fit" within one's workload. Participant I8, a mid-career librarian at a large university, commented, "People can be very creative and adept at tying those things together, you know if your research interests align nicely with [. . . ] your work at the service desk or teaching, [...] that's the ideal model that is sort of promoted around here." Participant 24, an early-career librarian also at a large university, said, "Most of us would be doing [...] presentations at professional associations or publications in professional literature [. . . ] you know a lot of it's about, somehow tied to the library." Librarians whose scholarship and professional-practice areas matched up used words like "alignment," "flow," or "fit." In contrast, two respondents from separate institutions whose research engaged with information science more broadly met with resistance from library administrators when trying to negotiate time for research: "I had a little bit of pushback that what I was doing was not real library work, and so I had to put forward a bit of a proof to say, yes, this is in fact research that a librarian should be doing and that I should be doing in this role," said one.

Accounting for one's time and demonstrating results when engaging in scholarship was important. When asked about an area they were exploring through the literature, one that they did not intend to turn into a "product," Participant 7 , 
an early-career librarian at a small university, said, "I wish I had more time just to explore things, but I feel a bit of pressure to, when I do start reading, to actually make something out of it [laughs]." Similarly, Participant 2I lamented,

And then the other challenge that we have is that you can't just go to a conference, right? [. .

.] If I went to a conference to like just learn, that is insufficient [. . .] you have to present or else

it doesn't count [...]. You really have to, everything has to count [...].

Most participants chose smaller, discrete, less time-consuming projects or products such as posters, peer review, or conference presentations, in part because it allowed them to produce tangible outputs in quantity. Participant 2, a mid-career librarian at a small institution, said, "I have those little things, so if we're doing something [...] new, let's write it up, get it out there. It might not be a peer-reviewed gold standard, but it's getting stuff out there." Similarly, Participant 5, an earlycareer librarian at a mid-sized university, picked "the low-hanging fruit," "the easy ones with deadlines," "chapters here, little articles there [.. . just to get that in my résumé, on my CV." Only one interviewee described developing a research program as a way of maximizing return on investment across their roles and responsibilities. Participant 24: "I've been thinking more about how faculty do it, and [. . . they kind of build on previous work more, which is a lot smarter [laughs] to do, rather than kind of reinventing the wheel each time." This comment suggests that in choosing oneoff research projects tied to their practice, librarians are using their time ineffectively: researching "ideas as they come up" requires one to continually start from scratch. In contrast, a "research program" or a "scholarship approach," as this librarian described it, is an investment in one's future research productivity, allowing one to "build on previous work."

For some interviewees, monetary compensation was a driver, and as a result they felt compelled to engage in scholarship even when it meant doing it on their own time. In this case, research was an externally imposed requirement, a "category" to fill for performance review. Participant 2I described having "overextended" themselves in research and professional service because they depended on merit pay in order to keep up with the cost of living. Another early-career librarian in a midsized institution described "getting ... involved in as many committees, going above and beyond as much as possible" and being "in people's faces" as strategies to secure a positive performance evaluation and merit pay.

Scholarship was conducted outside of work time because it required quiet, uninterrupted, and extended time. Working outside the library building and outside of "scheduled time" (Ylijoki and Mäntylä 2003) were often essential for reading and writing. Participant I9, an early-career librarian working at a large institution, "balanced" their research time between work and home. Participant 24 said, 
We don't have research days or anything like that [...]. And [ . . ] we don't have any hours or, so, you know it's, depending on how ambitious any of us wants to be, we can work on weekends and evenings.

Several participants talked about finding a project with personal significance to drive them to work on their own time. Participant 4, a mid-career librarian in a mid-sized institution, said, "Hopefully you find a project that lights a fire under you, that you're really passionate about, and because of that, you're compelled to do the work. For me, I haven't found that [.. .] yet [. . .], so it's hard to find the time." Participant 23, a midcareer librarian in a large university, commented, "All my research [...] has had a personal connection for me, it's made it very easy for me to say, 'Oh, I'll take a couple articles home with me, read them,' or work on the weekends."

\section{Professional Service}

Some librarians prioritized professional service over scholarship because it was often a part of their job, not an external requirement-it "fit" more easily within the workday. Some service work, like organizing conferences, had a regular cycle, making it align better with the rhythms of the academic year. In contrast, other forms of professional service, e.g., serving on hiring committees, was time-intensive. Because it was "high priority" and needed to be "wrapped up quickly," as Participant 15, a mid-career librarian in a large university, noted, it had to fit. Several people described service to the university, such as participating in the faculty association or collective bargaining, as a priority because it allowed them to engage with issues central to the university's mission. Moreover, unlike scholarship, which is often solitary, professional-service work is largely collaborative, making it more enjoyable for some.

In summary, the following passage is largely representative of UI5 librarians' experiences of the timescape of the neoliberal university and its impact on their scholarship and professional-service activities.

Interviewer: And how do you manage your workload?

Participant 24: [...] I try to as much as possible to prioritize the user [...] it kind of interrupts a lot of things, but I think that's important, so I'm okay with it. I have some sort of longer-term projects [. . . ] that are sort of always on my mind, I have a document I keep [...] and then it gets sad when things are still on the list for like a year, but that's how it is [chuckles]. [. . . Luckily, when the term's out, I have more time to do projects and research and stuff [...], but it can be challenging to prioritize it because you can kind of get swept away in some other things [...]. I've thought of [.. .] kind of experimenting with, kind of having particular days for certain things [...], like having a research day or something, and trying to do that, but that never seems to pan out [chuckles].

Although the majority of librarians described time or workload pressures, not all did. Participant 22, a late-career librarian at a large university, commented, 
"Yesterday was a very busy day for me, and it felt, it was good when I got home." Several interviewees described having autonomy over their time. Participant 6, a latecareer librarian in a small university, stated,

Other than the suggested percentage of time, you know the break up there [of professional practice, scholarship, and professional service], other than that, it's really up to us, we do have the freedom to get things done in their own way, so I think we're very lucky that way.

Successfully managing one's workload did not always mean having time for scholarship, however. Two contractually employed interviewees did not have research or professional-service responsibilities included in their job descriptions. A third, tenured librarian said they were no longer interested in scholarship as they were nearing retirement, preferring to devote their time to professional service instead. Finally, Participant I9 commented that while they had "the time and the freedom and encouragement" to engage in research, they didn't have "any kind of guidance" on how to go about it.

\section{Institutional Time Barriers}

I have outlined above the challenges librarians faced in making time for research within the workday. In the next section, I will examine structural barriers to research time that emerged from the interviews, namely, a lack of clarity surrounding what constitutes research, the devaluing of librarians' research, ambiguous policies and guidelines, and gaps between policy and practice surrounding performance evaluation, promotion, and tenure that left librarians unsure of how much time to spend on scholarly activities or how their performance would be assessed.

\section{What is Research?}

An important barrier to making time for research was the ambiguity surrounding what qualifies as such. In two institutions, only research within LIS or aligned with the strategic goals of the library "counted" toward performance evaluation, promotion, and tenure. This requirement not only proscribed scholarly interests and contributions but also resulted in an intensification of work.

Participant 23: So when I've wanted [.. . ] to defend my research work within my workload, I've had to negotiate that individually with my supervisor [.. . ] so basically that's officially completely, completely separate from my day job, right? Which of course [...] doesn't reflect reality, right? So there's a gap between my documented responsibilities and what my daily life is actually like.

In several universities, there was no requirement to engage in research; nonetheless, it was favourably perceived as long as it was done on one's own time. Participant I, a late-career librarian at a large university, commented, 
It's kind of there, it's nice if you do it. I know some librarians [. . . they've been involved in research grants, but they, they won't necessarily get time, they would be doing that research outside of their work time.

Participant 22 said that while there were no "official scholarship requirements [...], it looks good if you do it, of course. [...] That's a plus towards your tenure." This arrangement resulted in librarians taking on more work without requiring the university to provide structural supports. Commenting on their workload, Participant 23 said, "If it seems like you are managing, by all means take on that big research project, nobody's going to say don't do that, because [. . . it's prestigious for the university any time that you do anything that's an accomplishment, right?"

Participants believed that in the eyes of the university (and sometimes the library) administration(s), the value of librarians' research was ambiguous. Participant II, a late-career librarian at a small university, commented, "It's not clear to me though that our administration values those activities very much, I'm not sure how much weight is given when they are determining merit." Participant 4 , a mid-career librarian at a mid-sized university, said somewhat bitterly, "We get still very strong signaling from our administrators that we are not scholars, that [librarians' research] is not the same as [faculty] research." Moreover, librarians themselves did not always see themselves as scholars. In sum, it appears that librarians' research was valued by the institution inasmuch as it did not take time away from other work. "It's never conceived of or positioned as a priority for the institution or for academic librarians here. Yes, it's your responsibility, but you do that on your own time. Oh, and by the way, all of these other things are far more important and pressing," said Participant 4.

\section{Ambiguous Policies}

Unclear policies and gaps between policy and practice in the areas of performance evaluation, promotion, and tenure left librarians unsure of how much time to devote to scholarship or how their performance would be assessed. Participants at all but one institution reported issues of this kind. Provisions for taking time to engage in scholarship varied widely across and even within institutions: in one university, what to research and how much time one could spend on it were dictated by the library's strategic priorities and one's immediate supervisor.

In the majority of sites, librarians' relative efforts with regard to their roles and responsibilities were outlined according to percentages, such as 80 percent for professional practice and 20 percent for scholarship and professional service combined. Regardless of local particularities, however, there was a lack of consensus within and across institutions about how to understand these percentages, which describe effort, in terms of the material reality of work time. On the one hand, some 
librarians calculated percentages into hours or days. This served as a form of selfdiscipline: for example, colour-coding research activities in their calendar was a strategy Participant 5 used to "guilt" themselves into making time for it. On the other hand, several other interviewees expressed concern that such calculations would only reinforce an existing managerialist library culture and threaten their professional autonomy.

Participant 4: This is a perpetual question here, like is $[\mathrm{x}]$ percent like a half-day a week? [...] All sorts of my colleagues have said we have to be really careful about when we say we want half a day a week, because then we are telling the employer that we work 40 hours a week and we are essentially [...] willing to punch a clock, and that is a different conversation.

This latter group preferred taking a low-key approach with their respective administrators instead. Participant 24:

Most of us find that it's better just not to talk about it [chuckles] and just do it when you have time, and that seems to work a little bit better than trying to say, 'I want this particular time to do this.' Just do it when there's time.

Others found it easier to adjust their goals to align with academic cycles. Participant 20, an early-career librarian at a mid-sized university, said,

We're at the end of the winter term, we're coming into intersession where there's not that many classes [...], so I'll probably take more time to amp up some of the research that's been on hold this last term, and it just kind of has a natural flow.

Percentages and provisions in collective agreements appeared to have little material impact on librarians' ability to secure time to engage in scholarship, however. One librarian working in a small institution commented, "On paper we're allowed to take a full research leave. In practice, none have been approved." Several participants across institutions mentioned their supervisor's attitude toward research as a contributing factor in their ability to engage in research.

In a few institutions, the system of allocating percentages to professional practice, research, and service did not exist. Participant 23 said,

It's great to say librarians can do research, but what are the structures that actually like make that possible within the job? That's a whole other question. And for us it's mainly just left up to each individual to just make the time.

In one library, this was attributed to differences in professional roles: just as librarians did not share the same roles and responsibilities in the area of professional practice, they could not be expected to share the same responsibilities (or opportunities) in the area of scholarship. Participant I8 likened this to "compar[ing] apples to oranges": "we couldn't have one model that would fit all, I don't know if that would work," they said. 
Provisions for paid research leaves were mentioned by participants at six universities. (It is possible that such provisions existed at other institutions, however, since research leaves were not addressed directly but arose naturally in conversation.) Leaves were seen as an important means of making time for research because they represented a "big chunk" of uninterrupted time, as Participant I4, a mid-career librarian in a mid-sized university, said. In one institution where paid leaves did not exist, librarians had taken unpaid leaves for scholarship purposes. Even where provisions for dedicated research days or leaves did exist, a limited number of participants reported having taken advantage of them, perhaps because other duties were deemed more pressing or their positions would not be backfilled during their absence, creating additional work for their colleagues. Participant I, a late-career librarian in a large university, stated, "We can apply for [research] leave, and that's, that's a wonderful opportunity, the only the difficulty with that is that your unit is left with nobody when you go."

Early-career and precariously employed librarians were particularly disadvantaged by inconsistencies in policies and practices related to time for scholarship. Two librarians, each with less than five years' experience, working at separate institutions, described receiving mixed messages about the importance of scholarship from their colleagues and administrators. "It's hard to interpret what the expectations actually are," said Participant 3, an early-career librarian in a large university. Two of the five contractually employed librarians who participated in the study did not have research included in their position responsibility statements. Another was expected to engage in scholarship, but unlike their tenure-stream colleagues had no access to research leaves. Participant I2, who had held several contract positions at their current institution, none of which included scholarship, service, or funding for professional development, had to do research on their own time. In their view, these conditions of employment, which prevented them from building a record of scholarship, posed a barrier to their eligibility to compete for tenure-stream appointments even at their current place of work, effectively condemning them to a cycle of precarious employment.

\section{Agency and Resistance}

In keeping with neoliberal logics of resilience, flexibility, and entrepreneurialism, being a "successful" researcher was largely dependent on individual determination. Intrinsic motivation (and sometimes guilt) and self-regulation strategies such as blocking time in one's calendar or working outside of work time played a significant role. "Scholarship is, they are always applauded, but they do basically rest on the initiative and the curiosity and the drive of the individual," noted Participant 24. Moreover, trying to work with rather than against neoliberal temporal logics 
facilitated scholarship. For example, choosing smaller, practice-oriented projects enabled librarians to fit them within the workday. Practice-oriented scholarship and turning conference presentations into publications extended the impact of one's efforts, maximizing return on investment. Accepting and even internalizing the dominant "structured time" (Ylijoki and Mäntylä 2003) timescape of the neoliberal university, by working at an accelerated pace to meet externally imposed deadlines, was another strategy for success.

Finding a personal connection to one's scholarship, valuing scholarship as part of being an academic librarian, and engaging in it in order to problematize and improve libraries and the profession were all mentioned as facilitators of scholarship. Participant 23 said, "I try to be driven by my curiosity and by my, or sometimes by my exasperation, right? Like sometimes just problem-solving insofar as I have the freedom to do that [.. .]." This same participant talked about engaging in a large-scale research project as "a commitment to myself as a researcher and as a contributor, as a scholar." They kept a list of things that they had said no to, a gesture they found "unexpectedly powerful," and made a point of taking time to celebrate their achievements. Participant I4 described the pleasure of reading and the serendipity of discovery in an area of scholarly interest in terms of losing track of time and one's surroundings, evoking the concept of "timeless time":

I like reading a lot. Like I spend a lot of time reading and a lot of time, like when I get you know, searching the literature again I kind of go down that rabbit hole and I start reading again and I get really excited [laughs].

Although scholarship was primarily described as an individual activity, an important contributing factor was informal support among peers, a strategy that also runs counter to the neoliberal project. Two participants mentioned working collaboratively as a way to make time for research. In one institution, librarians advanced their collective scholarship by helping each other make time for it.

Participant 9 (mid-career, small university): We strongly encourage people to set aside days to do it and what we have found is that [.. .] if you say okay on this day you booked it, it's in your calendar, we won't schedule you for any meetings, we won't schedule you for desk on that day, that's your day. Then we end up taking it.

Over time, taking research leaves had also become more common at this institution. (Conversely, two librarians there remarked that some leave requests had met with resistance from library administrators.) Providing feedback on each other's work, and participating in research groups and journal clubs, were also mentioned by respondents in three institutions as collegial initiatives intended to build confidence, shared knowledge, and a culture of research. In contrast, librarians at two other universities, one mid-sized and one large, mentioned a lack of guidance and a weak culture of research as barriers. 
Finally, two people described their participation in this study as a way of supporting a fellow researcher. Participant 9 said,

Maybe it's just this feeling that library research is hard enough, and why make it harder by having a struggle to find people to talk to, so if I can give up you know an hour or whatever of my time, great, you know.

Similarly, Participant I5 stated, "I consider [my participation] as a contribution to scholarship, so I was happy to do this." Others commented on the value of the interview as an opportunity to pause and reflect.

\section{Discussion}

This study sheds new light on the role of time as a mechanism through which neoliberal governmentality is enacted in Canadian academic libraries. As Walker (2009, 484) makes clear, "academic capitalism requires both the reification of time and an internalization of the importance of managing time in a demonstrably efficient manner."

In keeping with Berkovich and Wasserman's (2017) examination of the cultural sense-making practices of Israeli academic librarians, Ui5 librarians had "internalized and integrated" elements of the discourses and practices of NPM, to some degree at least. Canadian librarians experienced the dictates of NPM as a need to engage in self-discipline and self-regulation. This was evident in the way they translated effort into time and in the pervasive use of calendaring to schedule, monitor, and record their use of time. Tracking their time and activities allowed them to demonstrate their productivity - and their value. Using one's calendar to "guilt" oneself into research or finding reasons to be "compelled" to work in the evenings and weekends also represent time as disciplinary power.

In keeping with work by Bansel and Davies (2005) and Sloniowski (2016), librarians in this study regularly put aside their research in favour of other duties because it did not "clearly lead, in a linear fashion, to a known, measurable, and institutionally recognised outcome" (Bansel and Davies 2005, 50). Meeting with students and faculty, teaching classes, managing budgets, and staffing service points were all more pressing, because they were scheduled or had deadlines and because they generated measurable outputs. As Sloniowski (2016) contends, librarians "struggle to find time to research and write because our [public] service work is considered more useful to the corporate goals of the university" (2016, 66I). Engaging in scholarship outside of work hours was reported by almost half of the interviewees (II out of 24).

The pressure to perform neoliberal subjectivities had a clear impact on the kinds of research academic librarians produced: discrete, time-limited, and practice- 
oriented research projects allowed them to manage their time and maximize their return on investment. ${ }^{12}$ Smaller, practice-oriented projects were the norm in part because they fit more easily within the accelerated "scheduled time" of the university. This finding is consistent with existing literature that demonstrates that librarians' reading and research activities are largely dictated by their professional practice, and that conference papers, posters, and presentations are preferred over publishing (Sugimoto et al. 20I4), but it does provide new insights into why this is the case. Trying to work with, rather than against, neoliberal timescapes by changing the kinds of research enquiry facilitates outputs and demonstrates "value."

Quality of time is an important factor in research productivity for both faculty and librarians (Fox 2007; Menzies and Newson 2007; Ylijoki and Mäntylä 2003). In keeping with research by Ylijoki and Mäntylä (2003) on the impact of NPM on time in Finnish universities, "timeless time," the kind of time conducive to scholarship, was rarely experienced by participants in the present study. Fragmented workdays posed barriers to reading, writing, and critical reflection at work. The present study also supports Fox's (2007) conclusion that balancing professional practice and scholarship in Canadian academic libraries is largely an individual matter. Being a "successful" researcher is dependent on intrinsic motivation and/or self-regulation: librarians in both studies reported engaging in scholarship during evenings and weekends. This was described by participants as showing "ambition," "passion," and "fire," and being "compelled" or "driven," all examples of performing neoliberal subjectivities. For some librarians in the present study, this was episodic; for others, it was a regular occurrence. Quality of time-extended periods of quiet uninterrupted time-was a key factor in the need to engage in research outside of work time. The experiences of libra rians in this study thereby suggest that the perceptions of CARL directors regarding librarians' research, as reported by Berg, Jacobs, and Cornwall (2013) are misguided: ${ }^{13}$ individual motivation and informal peer support, not systemic factors, were the most important factors contributing to their success as scholars. Moreover, librarians found systemic supports, where available, to be insufficient. In my view, the gap between librarians and directors can be attributed in no small part to conflicting organizational timescapes, that is to say, that directors of Canadian

I2. This finding suggests one possible answer to Sloniowski's $(2016,258)$ question: "how [does] the pressure to suppress both the emotions and the body impact the research scholars produce"? I3. Survey respondents were directors of comprehensive or medical-doctoral institutions, the same types of institutions as members of the Ui5 group. It is therefore possible to conclude that similar conditions exist in the UI5 universities I examined. This finding is also in keeping with results from the survey by Sugimoto et al. (2014), in which less than half of ARL libraries in the US reported having written policies regarding promotion and tenure. The following CARL libraries, listed from east to west, are also ARL members: McGill, Queen's, University of Toronto, York, University of Guelph, University of Waterloo, University of Western Ontario, University of Manitoba, University of Saskatchewan, University of Alberta, University of Calgary, Simon Fraser, and University of British Columbia. 
Ui5 libraries do not appear to account for differences in quality of time and their impact on librarians' research. Findings from the present study suggest that at least some Canadian academic librarians may be being held accountable to ambiguous performance standards and impracticable timescapes with regard to scholarship.

Ui5 librarians' complex and sometimes ambivalent responses and actions suggest (sub)conscious acceptance of the logics of NPM, subversive co-optation, and overt resistance to them. This finding contrasts with Berkovich and Wasserman's 2017 case study in that Israeli librarians did not appear to have a strong awareness of the discourses and practices of NPM. For example, prioritizing practiceoriented scholarship, the norm among the Canadian cohort, can be seen both as an acceptance of the productivity imperative of the neoliberal university, according to which quantity is more important than quality, and as a way of resisting the intensification of work by trying to regain control over one's time. And while selecting personally fulfilling research projects can also be seen as a rejection of the "practicality imperative" (Hudson 20I7) in librarianship and the timescape of the neoliberal university, such resistance came at a price in that it often required librarians to engage in these projects on their own time. Similarly, taking advantage of collaborative projects, which require one to be accountable to one's colleagues, challenged the neoliberal subjectivities of entrepreneurialism and competition.

For some participants, this complex interplay required considerable affective labour. Like their faculty counterparts, librarians' affective labour, the invisible work of managing emotions upon which the service economy depends, is characterized by anxiety; being mentally prepared for work at any time, by incessantly checking email, for example; and a compulsion to stay "constantly connected and on top of new information in one's field" (Sloniowski 2016, 658). It is also marked by "feelings of instability and being overloaded, and ... ongoing fears of being left behind" (Sloniowski 20I6, 658). Participant II was disillusioned with the "McDonaldized" environment of Canadian academic libraries and "pessimistic" about their future. Their colleagues were "burned out," "really lacking the will and the courage to push back and [.. .] question [.. .] some of these decisions," they said. As a commitment to themselves and the profession, they engaged in small daily acts of resistance, including offering (unsolicited) constructive feedback on strategic decisions and prioritizing their own professional development, scholarship, and professional service. In a similar vein, Participant I4 talked about the challenges of "going against the grain" in "a very conservative institution" and trying to use their research agenda to bring a more critical perspective to their professional practice.

Using Jeffress' (2008) work on postcolonial theories of resistance, Shahjahan (20I4) reviews models of resistance within the literature on neoliberalism in higher 
education. The strategies of resistance employed by participants align with dominant models identified by Jeffress, i.e., cultural, subversive, and oppositional resistance.

Shahjahan argues that while cultural and subversive resistance, both of which involve "saying no to power," can facilitate "more meaningful individual or collective forms of resistance in [higher education]" (2OI4, 224), they have limited potential to disrupt or overturn dominant logics. Shahjahan advocates instead for a "transformational resistance," one that "foregrounds individual agency as a core component in a praxis based on connection, human dignity and mutual interdependence" (2014, 228). "In this paradigm, resistance becomes 'freedom to,' rather than 'simply freedom from"' (2OI4, 228). The efforts of librarians in this study to build a shared culture of scholarship through informal peer supports and engagement in collective associations offer some promise as "freedom to" pursue a more critical research agenda and collective professional practice.

\section{Conclusion}

In this article, I have explored the impact of neoliberal timescapes, enacted through the policies and practices of New Public Management, on the scholarship and professional-service activities of information literacy librarians working in Canadian research-intensive (UI5) universities. Data was gathered during semi-structured interviews with 24 librarians and analyzed using thematic analysis (Braun and Clarke 2006) within a constructionist framework.

This research adds to the existing literature on librarians as researchers by highlighting the role of time as a key mechanism through which neoliberal governmentality is enacted in Canadian academic libraries. The results are significant, if not entirely unexpected: they suggest that NPM has imprinted on the quality of time and librarians' experiences of time in the workplace, effectively limiting librarians' ability to engage in scholarship and service activities during the workday. Public-service work was prioritized because it was time-sensitive, timedefined, and resulted in concrete, measurable outputs. Scholarship, which requires longer periods of quiet uninterrupted time, was regularly conducted outside of work schedules, during the evening and on weekends. The timescape of NPM also had an important impact on the kind of scholarship that librarians engaged in. Smaller, practice-related scholarship was the norm because it fit better with the neoliberal timescape of the academic library, could be more easily accomplished within the accelerated and fragmented time of the workday, and resulted in a higher number of outputs, key to success in an environment that values measurable outputs that contribute to institutional priorities above all.

In closing, I would like to mention that in its attempt to situate the labour and politics of knowledge production in the academic library within the broader context 
of the neoliberal globalization of higher education, this article represents what Sloniowski (20I6) describes as writing as a form of resistance. Regardless of any subversive intentions, however, in my annual report this paper will be seen as an output, a plus toward a positive performance evaluation and perhaps even a merit bonus. It is, after all, a product of its time-in more ways than one. This research was conducted outside the "structured time" of my workplace, during the "extended week" of many weekends and over the course of two paid professional leaves. While I was away, profiting from this "timeless time," my colleagues took on my administrative and teaching roles in addition to their own duties, no doubt putting their own scholarship on hold. I would like to acknowledge their labour, and their time, that made this work possible.

\section{ABOUT THE AUTHOR}

Karen P. Nicholson is Manager, Information Literacy, at the University of Guelph. She obtained her MLIS from McGill and her PhD (LIS) from the University of Western Ontario. Her research focuses on time/space, academic libraries, labour, and the university. She can be found online at @nicholsonkp.

\section{REFERENCES}

Adam, B. C. 1990. Time and Social Theory. Oxford, UK: Polity Press.

Adam, B. 2008. Of Timescapes. Futurescapes, and Timeprints. Lüneburg, Sweden. HTt P://Cite SEeRX.IST.PSU. EDU/VIEWDOC/DOWNLOAD;?DOI=IO.I.I.594.I 289\&REP=REPI \& T Y PE=PDF

Allen, D. 20II. "Information Behavior and Decision Making in Time-Constrained Practice: A DualProcessing Perspective." Journal of the American Society for Information Science and Technology 62 (II): 2I65-8I. HTTP://DOI.ORG/IO.IOO2/ASI.2I6OI

Anderson, K. 2013. “The Footprint and the Stepping Foot: Archival Records, Evidence, and Time." Archival Science I3 (4): 349-7I. HT T P S://DOI.ORG/IO.IO O //SIO5O 2-O I 2-9I93-2

Bansel, P., and B. Davies. 2005. "The Time of Their Lives? Academic Workers in Neoliberal Time(s)." Health Sociology Review I4 (I): 47-58.

Berg, S. A., H.L.M. Jacobs, and D. Cornwall. 2013. "Academic Librarians and Research: A Study of Canadian Library Administrator Perspectives." College \& Research Libraries 74 (6): 560-72. H T T://DOI. ORG/IO.5860/CRLI2-366

Berkovich, I., and V. Wasserman. 20I7. "Exploring Narratives of Non-Faculty Professionals in Neoliberal Higher Education: A Cultural Appropriation Perspective on Librarians." Studies in Higher Education I-I3. HTTP://DOI.ORG/IO.IO80/O3075079.20I7.I4I308I

Bossaller, J., C. S. Burns, and A. VanScoy. 2017. "Re-Conceiving Time in Reference and Information Services Work: A Qualitative Secondary Analysis.” Journal of Documentation 73 (I): 2-I7. H T T P://DOI. ORG/IO.IIO8/JD-03-2016-0O28

Braun, V., and V. Clarke. 2006. "Using Thematic Analysis in Psychology." Qualitative Research in Psychology 3(2): 77-IOI. HTTP://DOI.ORG/IO.II9I/I478088706QPO63OA

Bronstein, J. 20I4. "Creating Possible Selves: Information Disclosure Behaviour on Social Networks." Information Research: An International Electronic Journal I9 (I). HT TP://INFORMATIONR.NET/IR/I9-I/ PAPER609.HTML

Canadian Association of University Teachers (CAUT). 2017. "Librarians in Canada's Universities \& Colleges: State of the Profession 2000-20I4." CAUT Education Review. 
Chen, S.-Y. (Max), and S. Y. Rieh. 2009. “Take Your Time First, Time Your Search Later: How College Students Perceive Time in Web Searching." Proceedings of the American Society for Information Science and Technology 46 (I): I-I9. HTTP://DOI.ORG/IO.IOO2/MEET.2OO9.I 450460253

Corbin, J., and A. Strauss. 2008. Basics of Qualitative Research, 3rd ed. Oakland, CA: SAGE.

Crescenzi, A., R. Capra, and J. Arguello. 2013. "Time Pressure, User Satisfaction and Task Difficulty." Proceedings of the American Society for Information Science and Technology 50 (I): I-4. H T T P://DOI. ORG/IO.IOO2/MEET.I 4505OOII 2 I

Davies, B., J. Browne, S. Gannon, E. Honan, and M. Somerville. 2005. "Embodied Women at Work in Neoliberal Times and Places." Gender, Work \& Organization I2 (4): 343-62. H T T P://DoI.ORG/IO.IIII/ J.I $468-0432.2005 .00277 . x$

Davies, E., and P. J. McKenzie. 2002, May-June. "Time Is of the Essence: Social Theory of Time and Its Implications for LIS Research." 3oth Annual Conference of the Canadian Association for Information Science, Toronto, I-I3. HTTPS://IR.LIB.UWO.CA/FIMSPRES/26/

Detlor, B., and V. Lewis. 2015. "Promoting Academic Library Research through the 'Faculty-MemberIn-Residence' Program." Journal of Academic Librarianship 4I (I): 9-I3. H T T P S:// DOI.ORG/IO.IOI6/J. ACALIB.2OI4.II.OII

Drabinski, E. 20I4. “Toward a Kairos of Library Instruction." Journal of Academic Librarianship 40 (5): 480-85. HTTP://DOI.ORG/IO.IOI6/J.ACALIB.2OI4.06.002

Elliott, B. 20I8. "Work, Culture, and Play in the Neoliberal Condition." Information, Communication \& Society 2I (9): I279-92. HTTP://DOI.ORG/IO.IO80/I369II8X.20I8.I 476568

Flierl, M., H. Howard, W. Zakharov, D. Zwicky, and S. Weiner. 20I8. "First-Year International Undergraduate Students and Libraries." Portal: Libraries and the Academy I8 (3): 535-58. H T T P ://DOI. ORG/IO.I353/PLA.2OI8.0032

Fox, D. 2007. "Finding Time for Scholarship: A Survey of Canadian Research University Librarians." Portal: Libraries and the Academy 7 (4): 45I-62. HT Ps://MUSE.JHU.EDU/ARTICLE/2 23645

Giroux, H. A., and S. S. Giroux. 2004. Take Back Higher Education: Race, Youth, and the Crisis of Democracy in the Post-Civil Rights Era. New York: Palgrave.

Glassman, J. 20I7, Oct. I8. "The Innovation Fetish and Slow Librarianship: What Librarians Can Learn from the Juicero." In the Library with the Lead Pipe. Http://wWW. InTHELIBRARYwiththeleadpipe. ORG/2OI7/THE-INNOVATION-FETISH-AND-SLOW-LIBRARIANSHIP-WHAT-LIBRARIANS-CAN-LEARNFROM-THE-JUICERO/

Gregory, L., and S. Higgins. 20I8. "In Resistance to a Capitalist Past: Emerging Practices of Critical Librarianship." In The Politics of Theory and the Practice of Critical Librarianship, edited by K. P. Nicholson and M. Seale, 2I-38. Sacramento: Library Juice Press.

Hancock, P., and A. Spicer. 20I0. "Academic Architecture and the Constitution of the New Model Worker." Culture and Organization I7 (2): I-I9. HT TPS://DOI.ORG/IO.IO80/I 475955I. 2 OII.544885

Harris, R. M. 1992. Librarianship: The Erosion of a Woman's Profession. Norwood, NJ: Ablex.

Hartel, J. 20I0. "Time as a Framework for Information Science: Insights from the Hobby of Gourmet Cooking." Information Research I5: 3. HTTP://WWW.INFORMATIONR.NET/IR/I5-4/COLIS7 I5.HTML

Harvey, D. 2007. A Brief History of Neoliberalism. New York: Oxford University Press.

Hicks, D., and T. J. Schindel. 20I6. "Time Changes Things: Time as a Linguistic Resource for Professionals in Information-Intensive Fields." Canadian Journal of Information and Library Science 4O (I): I-26.

Hoffmann, K., S. A. Berg, and D. Koufogiannakis. 20I4. "Examining Success: Identifying Factors that Contribute to Research Productivity across Librarianship and Other Disciplines." Library and Information Research 38 (II9): I3-28. HTTPS://DOI.ORG/IO.29I73/LIRG639 
Hollister, C. V. 20I6. "An Exploratory Study on Post-Tenure Research Productivity among Academic Librarians." Journal of Academic Librarianship 42 (4): 368-8I. HT T PS://DOI.ORG/IO.IOI6/J. ACALIB.2OI6.04.02I

Hood, C. 199I. “A Public Management for All Seasons?" Public Administration 69(I): 3-I9. H t T P://DoI. ORG/IO.IIII/J.I467-9299.I99I.TBOO779.X

Hudson, D. J. 20I7. “The Whiteness of Practicality." In Topographies of Whiteness: Mapping Whiteness in Library and Information Science, edited by G. Schlesselman-Tarango, 203-34. Sacramento: Library Juice Press.

Jeffress, D. 2008. Postcolonial Resistance: Culture, Liberation and Transformation. Toronto: University of Toronto Press.

Jones, L. M., K. D. Wright, M. K. Wallace, and T. Veinot. 20I8. “"Take an Opportunity Whenever You Get It': Information Sharing among African-American Women with Hypertension." Journal of the Association for Information Science and Technology 69(I): I68-7I. H T T P S://DOI.ORG/IO.IO O 2/ASI. 23923

Kennedy, M. R., and K. R. Brancolini. 2012. "Academic Librarian Research: A Survey of Attitudes, Involvement, and Perceived Capabilities." College \& Research Libraries 73 (5): 43I-48. н T T P S://DOI. ORG/IO.5860/CRL-276

Kont, K. 2013. "Cost Accounting and Scientific Management in Libraries: A Historical Overview." Journal of Management History I9 (2): 225-40. HT TP://DOI.ORG/IO.IIO 8/I 75II 34 I 3 II 307390

Lanclos, D., and A. Asher. 20I6. “'Ethnographish': The State of the Ethnography in Libraries.” Weave Journal of Library User Experience I (5). H T T P://DX.DOI.ORG/IO.3998/WEAVE.I 2535642.00OI.5O3

Lincoln, Y. S., and E. G. Guba. 1986. "But Is It Rigorous? Trustworthiness and Authenticity in Naturalistic Evaluation." New Directions for Program Evaluation 30: 73-84. H T т P:// D I. Wile y. COM/IO.IOO2/EV.I 427

Lucyk, K., K. Tang, and H. Quan. 20I7. "Barriers to Data Quality Resulting from the Process of Coding Health Information to Administrative Data: A Qualitative Study.” BMC Health Services Research I7 (I). HTTPS://DOI.ORG/IO.II86/SI29I3-OI7-2697-Y

Menzies, H., and J. Newson. 2007. "No Time to Think: Academics' Life in the Globally Wired University." Time \& Society I6 (I): 83-98. HT T P://DOI.ORG/IO.II 77/096I 463X07074IO3

Mizrachi, D., and M. J. Bates. 2013. “Undergraduates' Personal Academic Information Management and the Consideration of Time and Task-Urgency." Journal of the American Society for Information Science and Technology 64 (8): I590-I6O7. HTTP://DOI.ORG/IO.IOO2/ASI. 22849

Moss, D. 2006. Gender, Space and Time: Women and Higher Education. Lanham, MD: Lexington.

Most, L. R. 20II. "The Rural Public Library as Place: A Theoretical Analysis." Advances in Library Administration and Organization 30: 5I-I49. HT T P ://DOI.ORG/IO.I IO8/sO 732 067I(20II)0000030005

Mountz, A., A. Bonds, B. Mansfield et al. 2015. "For Slow Scholarship: A Feminist Politics of Resistance through Collective Action in the Neoliberal University." ACME International E-Journal for Critical Geographies I4 (4): I235-59.

Nicholson, K. P. 2015. "The McDonaldization of Academic Libraries and the Values of Transformational Change." College \& Research Libraries 76 (3): 328-38. H T P://DOI.ORG/I 0.5860/CRL.76.3.328

- 2016. “Taking Back' Information Literacy: Time and the One-Shot in the Neoliberal University." In Critical Library Pedagogy Handbook. Volume I, Essays and Workbook Activities, edited by K. McElroy and N. Pagowsky, 25-39. Chicago: Association of College \& Research Libraries.

2018. "Academic Librarians and the Space/Time of Information Literacy, the Neoliberal University, and the Global Knowledge Economy." Unpublished doctoral dissertation, Faculty of Information and Media Studies, University of Western Ontario. HTTPs://IR.LIB.UWO.CA/CGI/ VIEWCONTENT.CGI?ARTICLE $=7938 \&$ CONTEXT $=$ ETD 
Olssen, M., and M. A. Peters. 2005. "Neoliberalism, Higher Education and the Knowledge Economy: From the Free Market to Knowledge Capitalism." Journal of Education Policy 20 (3): 313-45. HT T://DOI. ORG/IO.IO80/02680930500IO87I8

Orlu, A. D. 20I6. "Information Seeking Behaviour of Masters Students: Affective and Behavioural Dimensions." Library Philosophy and Practice 20I6 (I). H t T P://Digitalcom Mons.unL.edu/ LIBPHILPRAC/I 387 /

Panahi, S., J. Watson, and H. Partridge. 2016. "Information Encountering on Social Media and Tacit Knowledge Sharing." Journal of Information Science 42 (4): 539-50. H T T P s:// D I. ORG/IO.II77/OI6555I5I5598883

Parbhoo, Naailah, and Ina Fourie. 20I7. "Effective Use of Value-Added Features and Services of Proprietary Databases in an Academic Context." Information Research: An International Electronic Journal 22 (I). HTTP://WWW.INFORMATIONR.NET/IR/2 2-I/ISIC/ISICI6I 4.HTML

Patton, M. Q. 1999. “Enhancing the Quality and Credibility of Qualitative Analysis." Health Services Research 34 (5, pt. 2): II89-I2O8.

Poirier, L., and L. Robinson. 20I4. "Informational Balance: Slow Principles in the Theory and Practice of Information Behaviour." Journal of Documentation 70 (4): 687-707. H T TP://DOI.ORG/IO.I IO8/JD-O 82OI3-OIII

Quinn, B. 2000. “The McDonaldization of Academic Libraries?” College \& Research Libraries 6I (3): 248-6I. HTTP://DOI.ORG/IO.5860/CRL.76.3.339

Rottenberg, C. 20I3. “The Rise of Neoliberal Feminism.” Cultural Studies 28 (3): 4I8-37. H t t P://Doi.org/IO .1080/09502386.20I3.85736I

Ryan, P., and L. Sloniowski. 20I3. "The Public Academic Library: Friction in the Teflon Tunnel." In Information Literacy and Social Justice, edited by L. Gregory and S. Higgins, 275-300. Sacramento: Library Juice Press.

Sassen, C., and D. Wahl. 20I4. "Fostering Research and Publication in Academic Libraries." College \& Research Libraries 75 (4): 458-9I. HTTPS://DOI.ORG/IO.5860/CRL.75.4.458

Savolainen, R. 2006. “Time as a Context of Information Seeking." Library \& Information Science Research 28 (I): IIO-27. HTTPS://DOI.ORG/IO.IOI6/J.LISR.2OO5.II.OOI

Shahjahan, R. A. 20I4. “From 'No' to 'Yes': Postcolonial Perspectives on Resistance to Neoliberal Higher Education." Discourse 35 (2): 219-32. HTtP://DOI.ORG/IO.IO80/OI596306.20I2.745732

2015. "Being 'Lazy' and Slowing Down: Toward Decolonizing Time, Our Body, and Pedagogy." Educational Philosophy and Theory 47 (5): 488-50I. H T TP://DOI.oRG/IO.IO80/OOI 3 I 857.20I 4.880645

Shenton, A. K. 2004. "Strategies for Ensuring Trustworthiness in Qualitative Research Projects." Education for Information 22 (2): 63-75.

Shore, C. 2008. "Audit Culture and Illiberal Governance." Anthropological Theory 8 (3): 278-98. нт т Ps:// DOI.ORG/IO.II77/I 4634996080938 I5

20I0. "Beyond the Multiversity: Neoliberalism and the Rise of the Schizophrenic University." Social Anthropology I8 (I): I5-29. HT T PS://DOI.ORG/IO.I I I I/J.I 469-8676.2009.00094.X

Slaughter, S., and L. Leslie. 1997. Academic Capitalism: Politics, Policies, and the Entrepreneurial University. Baltimore: Johns Hopkins University Press.

Sloniowski, L. 2016. “Affective Labor, Resistance, and the Academic Librarian." Library Trends 64 (4): 645-66. HTtPS://DOI.ORG/IO.I353/LIB.2OI6.OOI3

Spence, L. K. 2015. Knocking the Hustle: Against the Neoliberal Turn in Black Politics. Brooklyn: Punctum.

Sugimoto, C. R., A. Tsou, S. Naslund, A. Hauser, M. Brandon, D. Winter, C. Behles, and S. C. Finlay. 2014. "Beyond Gatekeepers of Knowledge: Scholarly Communication Practices of Academic Librarians and Archivists at ARL Institutions." College \& Research Libraries 75 (2): I45-6I. HT T P ://DOI.ORG/IO.5860/ CRLI $2-398$ 
Thomas, R., and A. Davies. 2002. "Gender and New Public Management: Reconstituting Academic Subjectivities." Gender, Work \& Organization 9 (4): 372-97. H T T P s://DOI.ORG/IO.I I I I/I 468-0432.00 I 65

Walker, J. 2009. "Time as the Fourth Dimension in the Globalization of Higher Education." Journal of Higher Education 8O (5): 483-509. HT TP://DOI.ORG/IO.I353/JHE.0.OO6I

Yevelson-Shorsher, A., and J. Bronstein. 2018. "Three Perspectives on Information Literacy in Academia: Talking to Librarians, Faculty, and Students." College \& Research Libraries.

Ylijoki, O.-H., and H. Mäntylä. 2003. "Conflicting Time Perspectives in Academic Work." Time \& Society I2 (I): 55-78. HT TP://DOI.ORG/IO.II77/O96I463XO3OI 2001364 
APPENDIX A: UI5 ENGLISH-LANGUAGE MEMBER UNIVERSITIES, SORTED BY TOTAL ENROLMENT, LOW TO HIGH

\begin{tabular}{|c|c|c|c|c|}
\hline Institution & $\begin{array}{c}\text { Undergraduate } \\
\text { Enrolment }\end{array}$ & $\begin{array}{c}\text { Graduate } \\
\text { Enrolment }\end{array}$ & $\begin{array}{c}\text { Total } \\
\text { Enrolment }\end{array}$ & $\begin{array}{c}\text { Research } \\
\text { Income (in \$ } \\
\text { millions) }\end{array}$ \\
\hline Dalhousie & I4 324 & 3395 & I8 440 & $\mathrm{I} 42$ \\
\hline Saskatchewan & I7 379 & 3 II5 & 20494 & 158 \\
\hline Queen's & I9 862 & $4 \mathrm{I} 86$ & 24042 & $\mathrm{I} 68$ \\
\hline McMaster & 25424 & 4344 & 29735 & 325 \\
\hline Manitoba & 25363 & 3748 & 29759 & $\mathrm{I} 37$ \\
\hline Western & 25196 & 5433 & $306 I I$ & 239 \\
\hline Calgary & 25818 & 6019 & 31802 & 283 \\
\hline Waterloo & 29782 & $5 \mathrm{I} 28$ & 34910 & $\mathrm{I} 37$ \\
\hline McGill & $2874 \mathrm{I}$ & $94 \mathrm{II}$ & 38 O3I & 483 \\
\hline Alberta & 31 904 & 7598 & 39459 & 452 \\
\hline Ottawa & 35609 & 6327 & 41905 & 302 \\
\hline British Columbia & 47732 & IO 552 & 58282 & 520 \\
\hline Toronto & 65139 & I5 250 & 80389 & I I90 \\
\hline
\end{tabular}

SOURCE

"Ui5 Group of Canadian Research Universities." n.d. Ui5 Group of Canadian Research Universities. Retrieved from HTтP://UI5.CA. 


\section{Theme: Background Information}

- How did you become an information literacy librarian?

\section{Theme: Information Literacy}

- Tell me about your information literacy work.

- How many classes do you typically teach in a given semester? In a given year?

- What is important to you about this work?

- How do others on campus feel about / perceive this work (students, faculty, administrators, other librarians)? How do you know?

- In your view, how does information literacy fit within the broader goals of higher education?

\section{Theme: Change}

- How has information literacy work changed since you started?

- How has librarianship changed?

- How has your work changed?

- How has the university changed?

- Has there been any change in the way that libraries are staffed during your time there?

\section{Theme: Environment}

- Tell me about your university.

- What does the university value? How do you know?

- What are the main drivers / forces that impact your work?

- What role do documents such as standards or guidelines play in your work?

- Are there other policy documents that play a role in your work?

- Tell me about assessment in your library.

- What are the main barriers to you in the performance of your work?

- What are the chief facilitators?

- How do you manage your workload?

\section{Theme: Scholarship}

- What is the status of librarians at your library (e.g., are they faculty? academic staff? other?)

- What is your status?

- Tell me about the scholarship and service requirements for librarians at your library.

- How do these fit with your information literacy work?

- How do you make time for scholarship and service?

- What do you read?

\section{Closing}

- If there were one thing you could change about your work, what would it be?

- Is there anything else you want to share with me? 